\title{
A Novel Optimization Algorithm for Reliable Energy Generation Based on Wind, Solar and Fuel Cell
}

\author{
Tara Khayyamim, Khosrow Hajsadeghi, and Abolghasem Zabihollah
}

\begin{abstract}
Concerns about fuel cost, pollution and global warming has made it necessary to look for new energy solutions. Renewable energies are environmentally friendly, not cheap at the beginning but naturally available at a constant rate and wide spread, unlike fossil fuels that are localized in limited places. To generate environmentally friendly power we consider two renewable energy resources: wind and photovoltaic, and a clean alternative energy (AE): fuel cells. In order to have a reliable and cost efficient power generating system, an optimization algorithm based on genetic algorithm is proposed. The proposed system has been tested for different scenarios and has been proven to be a reliable power generating system for various situations.
\end{abstract}

Index Terms-Genetic algorithm, hybrid energy systems, renewable power generation.

\section{INTRODUCTION}

Fuel cost, pollution and global warming has triggered the search for new energy solutions. Renewable and alternative energies have proven to be useful in this matter. Renewable energy (RE) is the energy that comes from natural resources such as sunlight, wind, rain, tides, waves and geothermal heat, which are naturally replenished at a constant rate. Renewable energy resources and significant opportunities for energy efficiency exist over wide geographical areas, in contrast to traditional energy sources, which are concentrated in a limited number of countries. Renewable energies need higher investment at the beginning but they are naturally available in a constant rate. Rapid deployment of renewable energy which results in diversification of energy sources, would result in significant energy security and economic benefits.

To generate environmentally friendly power we consider two renewable energy resources: wind and photovoltaic, and a clean alternative energy (AE): fuel cells. A few renewable energy sources like wind turbine (WT) and solar (PV), are clean abundantly available, and well developed, while some others like fuel cells (FC) are in their advanced development stage. The use of wind energy, however, is not evenly distributed around the world. By the end of 2001, the total operational wind power capacity worldwide was $23,270 \mathrm{MW}$. Of this, $70.3 \%$ was installed in Europe, followed by $19.1 \%$ in North America, $9.3 \%$ in Asia and the Pacific, $0.9 \%$ in the Middle East and Africa and $0.4 \%$ in South and Central

Manuscript received May 8, 2015; received October 23, 2015.

Tara Khayyamim and Khosrow Hajsadeghi are with the Department of Electrical Engineering, Sharif University of Technology, Iran (e-mail: tarakhayyam@gmail.com,ksadeghi@ee.sharif.edu).

Abolghasem Zabihollah is with the School of Science and Engineering, Sharif University of Technology, Kish Island, Iran (e-mail: zabihollah@sharif.edu).
America [1]. The applications of PV systems have become more widespread in both developed and developing countries. $\mathrm{PV}$ is scalable from very small to very large and easy to integrate with existing power converters. PV and WT have become the most promising sources of energy since their energy sources are free and sustainable.

The intermittent nature of many RE resources reduces their reliability, due to daily and seasonal changes. In order to improve these systems performance, the hybrid combination of two or more of these generation technologies along with storage and/or AE power generation system have been proposed. In general, hybrid systems convert all their sources into one form (typically electrical) and/or store the energy into some form (chemical, thermal, mechanical flywheel, etc.)

Hybridization generally increases the system reliability, however, this depends on proper technology selection and generation unit sizing. Storage is an essential part of a hybrid $\mathrm{RE} / \mathrm{AE}$ power generation system. Capacity-oriented energy storage technologies, such as hydrogen storage, generally do not have fast response time and are used for long-term energy storage/release for managing slow load variations. On the other hand, access-oriented storage devices with fast response time, such as batteries, flywheels and super capacitors, are used for responding to short time disturbances, such as fast load transients and for power quality issues [2].

In the specific case of solar, wind and FC hybrid system that is our focus, the fuel cell is used to suppress the fluctuations of the photovoltaic and wind turbine output power. The photovoltaic and wind turbines are controlled to track the maximum power point at all operating conditions. The fuel cell is controlled to supply the deficit power between the load power demand and the generated power of the combined photovoltaic and wind turbine sources.

\section{POWER MODELING}

\section{A. PV Model}

The photovoltaic module is a simplified model which converts solar irradiance and ambient temperature data into electrical active power depending on the surface area of the module. The nominal operating conditions such as ambient temperature, cell temperature and radiation are parameters which may be chosen according to the specific PV panel in use. The efficiency is modeled to decrease at higher ambient temperatures, depending on a temperature coefficient which depends on the type of PV panel. The presented model is not a component based model like a diode PV model. It should rather be used to represent the behavior of a PV module as a source within an electric system. 


\section{1) Formulation}

At first, the cell temperature Tcell is calculated from the ambient temperature and the solar irradiance data, depending on the nominal operating conditions [3]:

$$
T_{\text {cell }}=T_{\text {ambient }}+\left(T_{\text {NOCT }}-T_{\text {ambient, NOCT }}\right) \frac{I r r}{I r r \text { NOCT }}
$$

Now, the efficiency $\eta$ is updated according to the difference between $T_{\text {cell }}$ and $T_{\mathrm{NOCT}}$, weighted with the temperature coefficient for efficiency [4].

$$
\eta=\eta_{\text {Tref }}\left[1-\beta_{\text {ref }}\left(T_{C}-T_{\text {ref }}\right)\right]
$$

Finally, the active power output is given as [3]

$$
P=I r r \times \text { area } \times \eta
$$

2) PV cost

The fitness function of the optimization algorithm, discussed later in optimization section, is based on components cost. Our chosen economical approach is the concept of ACS (annualized cost of system) [5]. Based on the market research and the literature the PV cost is determined to be $\$ 5000$ per $\mathrm{kWh}$ with zero operation and maintenance (O\&M) cost and the BP Solar 2150S 150W module which requires $10 \mathrm{~m}^{2}$ per $\mathrm{kW}$ area.

\section{B. Wind Turbine Model}

The wind turbine model is a power curve model which, similarly to the solar PV generator, calculates an active power output depending on turbine specifications as well as the wind profile and air density. This is a function based simplified model, without the mechanical information or the type of electrical generator, used to represent a power source within an electrical system.

\section{1) Formulation}

The active power curve of a wind turbine is described by the (4) [3]:

$$
P=C_{p} \varepsilon_{g} \varepsilon_{b} \frac{1}{2} \rho A v^{3}
$$

where $1 / 2 \rho A v^{3}$ is the power of the wind acting on a surface $A$, and the factors $c p \varepsilon g \varepsilon b$ are limiting factors on the actual power exploitation which varies depending on the specific type of wind turbine and is limited by 0.593 according to Betz' law [3].

\section{2) WT cost}

Based on the market research and the literature values, the Furhlander30 WT has been chosen. It has 13 m rotor diameter and $26 \mathrm{~m}$ of tower height [6]. The initial cost has been taken as $\$ 78000$ and the O\&M cost of the considered WT is $\$ 24740$ per $30 \mathrm{~kW}$ with zero replacement cost.

\section{Fuel Cell Model}

The chosen electrolyzer (ELC) cost values has been determined as $3128 \$ / \mathrm{kWh}$ while the replacement and maintenance costs are $1 / 2$ and $1 / 20$ of the capital cost, respectively. FC cost value of the system is $\$ 5000$ per $\mathrm{kWh}$, and the maintenance cost is $\$ 0.1$ per hour. For the hydrogen tank (HT), HT and storing costs for $3.2 \mathrm{~kg}$ hydrogen is determined to be $\$ 2288$ while the replacing cost is $\$ 195$ and maintenance cost is $\$ 9$ per year for the system [7].

\section{OPTIMIZATION}

In order to have a reliable and cost efficient power generating system, an optimization algorithm based on genetic algorithm has been proposed. Fig. 1 shows the diagram of the proposed algorithm in which the GA block represents the genetic algorithm.

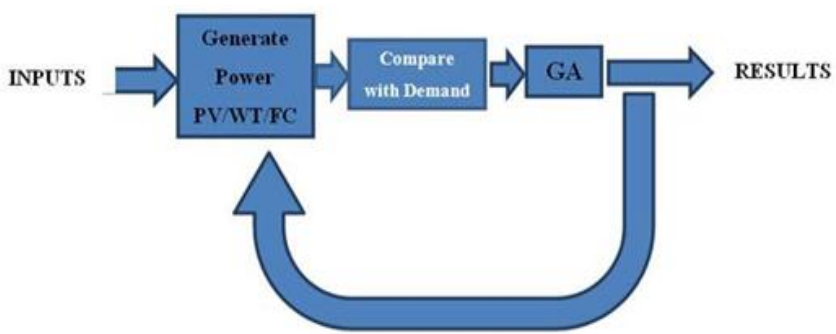

Fig. 1. Algorithm's diagram.

Considering the inputs, the very first generation is created in "Generate Power". The generated power is compared with demand power, if it is larger than the demand then with the relatively good fitness $(f>1)$ it goes to the process of GA. If the generated power does not match input demand (lower power than load) the comparison code generates a relatively low fitness $(f<1)$ and then continues with GA process. Since the GA generates and keeps populations (gens) with best (higher) fitness, it generates as much power as the demand. The cost values are considered by the algorithm such that the lowest cost solution which meets the demand is generated.

\section{SCENARIOS}

\section{A. Scenariol}

In this scenario, the system is designed for the $1 \mathrm{MW}$ peak demand. As it is in the following, we consider a constant $1 \mathrm{MW}$ demand for each scenario in order to compare each system's reliability and cost efficiency factor. The inputs to the algorithm are from Kish Island weather center at first of November. The first two systems use solar and wind energy alone, and their output indicates that they cannot meet the demand. In order to solve this issue another system is presented in which the power sources are the solar, wind and fuel cell. Fig. 2 shows this hybrid system outputs. As it is demonstrated with the addition of fuel cell in our power sources, we have a reliable system which generates enough power to reach the demand during all hours. The purple line is summation of generated power from solar, wind and fuel cell sources. As the figure shows the purple line matches the black dots that represent the demand. In the represented system the size of the solar source and wind farm are not extended and the fuel cell package solves the reliability issue. The total initial cost of this hybrid design will be $\$ 20265468$. 


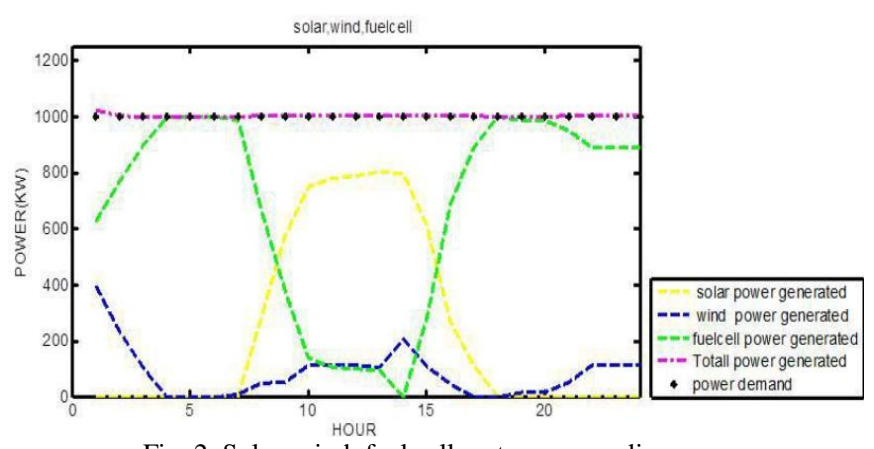

Fig. 2. Solar, wind, fuel cell system power diagram.

\section{B. Scenario 2}

Different systems have been discussed in scenario 1 and here we chose the reliable hybrid system, introduced last, to put it into test for different weather conditions. In order to do that, a day (first of May, August, February and November) from each season has been chosen. The weather data is from Kish Island weather center. In this scenario, the capacity of each source is chosen the same as in Scenario 1, therefore the initial cost is the same as scenario 1. As in scenario 1 the system will face $1 \mathrm{MW}$ demand. In the matter of cost, as it is mentioned above the initial cost will be remained constant. The initial cost of the designed solar field is $\$ 5005000$, the wind farm is $\$ 2574000$ and the fuel cell package that includes electrolyser and hydrogen tank is $\$ 12686468$. There is zero replacement cost for PV, WT and HT however $\$ 6545880$ has been considered for FC and ELC.

The test results for this scenario indicate that the designed hybrid system is reliable in each season in the given location. With the aid of our chosen optimization method proper coefficients have been found in order to have low operational cost power in the given situation. Apart from the initial cost, these 4 days have different O\&M costs. For example the cost on first of August is nearly 4 times of the first of May cost. This diversity is due to the high cost of fuel cells needed for 1st of August. The algorithm tries to decrease the system energy cost but it favors reliability over cost. The proposed system can, however, achieve financial through selling its extra power. For example in the first of May, if the full capacity of wind farm has been used, there is extra power to compensate for some of the cost. Therefore, we strongly suggest to use the full capacity of the sources when it is possible, and sell the extra power.

\section{Scenario 3}

In this scenario, we consider a practical load that belongs to the water pumping center in Mashhad, Iran. This center currently has some power problems. They need to reduce their electrical power expenses. In order to solve their problem we suggest a renewable hybrid system that can generate enough power to answer their electricity demand. This way they can independently generate their power needs Of course this project does not solve their expense problems immediately but it is a promising plan for their future. The presented system is designed for the worst case scenario therefore each source capacity is set to 5.5MW. So we have 5.5MW solar field with $\$ 27527500$ initial cost, 5.5MW wind farm that costs $\$ 14157000$, and $\$ 69775574$ fuel cell system that includes ELC and HT. In order to demonstrate the designed system functionality, the system has been tested with the conditions of Mashhad weather data in 5th of June (a randomly chosen day) and the hourly requested demand. The power demand is almost constant due to urban water usages in day time and agricultural usages at night.

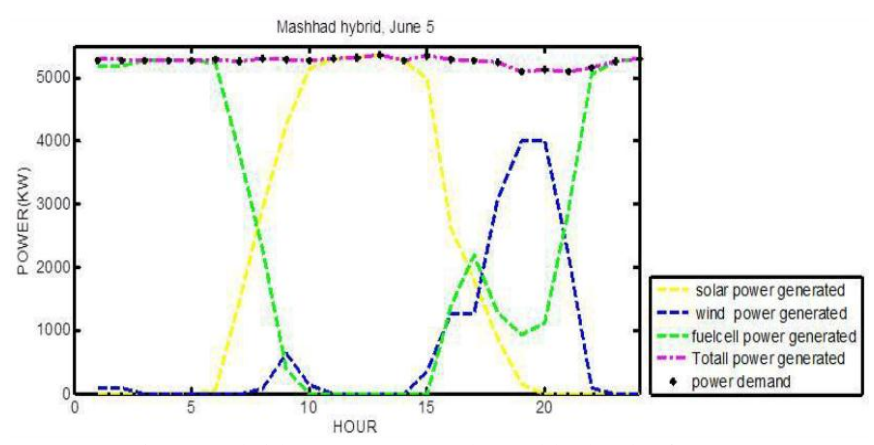

Fig. 3. Hybrid power generated, Mashhad, 5th of June.

Fig. 3 demonstrates the system power output for the 5 th of June. The purple line that illustrates the designed system generated power, match the requested demand all day long. These results prove that the proposed hybrid system will be reliable not only in theoretical situations but also in practical ones.

\section{CONCLUSION}

Scenario 1 indicates that due to the intermittent nature of solar energy and wind power, systems that only use these REs independently are not reliable. We can also conclude that just expanding the capacity of the RE would not solve the problem. Another conclusion which can be drawn is that since O\&M cost of solar fields are zero, our first option in any hybrid system that use PVs as one of their energy sources is to use full capacity of the solar source.

In order to solve the reliability issue another system was presented that uses FC to suppress the fluctuations of the photovoltaic and wind turbine output power. This system has been put into examination in scenario 2. Different weather conditions were set as the system input. The investment cost of the designed solar field is $\$ 5005000$, the wind farm is $\$ 2574000$ and the fuel cell package that includes electrolyser and hydrogen tank is $\$ 12686468$. There is zero replacement cost for PV, WT, and HT, however, $\$ 6545880$ has been considered for FC and ELC. With the aid of our chosen optimization method, the algorithm tries to minimize the system energy cost but it favors reliability over cost. The system can compensate some of the development cost through selling of its extra power. As indicated on the first of May, if the full capacity of wind farm is used there is good amount of extra power. Although these REs have high investment costs, in long term they can reimburse those costs because they do not need to pay for fuel constantly. Eventually scenario 3 results prove that the proposed hybrid system will generate reliable power not only in theoretical situations but also in practical ones.

\section{REFERENCES}

[1] T. Ackermann and L. Soder, "An overview of wind energy-status 2002,” Renewable Sustainable Energy Review, pp. 61-67, 2002. 
[2] M. H. Nehrir, H. Aki, R. Ramakumar, J. Bing, Z. Miao, and Z Salameh, "A review of hybrid renewable/alternative energy systems for electric power generation: Configurations, control, and applications," IEEE Transaction on Sustainable, pp. 392-403, 2011.

[3] K. Togawa and M. Schumacher, "Report on component models and the neighborhood integrated system model," Aachen, RWTH, 2013.

[4] E. Skoplaki and J. A. Palyvos, "On the temperature dependence of photovoltaic module electrical performance: A review of efficiency/power correlations," Solar Energy, pp. 614-624, 2009.

[5] S. Rahimi, M. Meratizaman, S. Monadizadeh, and M. Amidpour, "Techno-economic analysis of wind turbineePEM fuel cell hybrid system in standalone area," Elsevier, pp. 381-396, 2014.

[6] Fuhrländer FL 30 (Turbine). [Online]. Available: http://en.wind-turbine-models.com/turbines/278-fuhrl-nder-fl-30

[7] M. Beccali, S. Brunone, M. Cellura, and V. Franzitta, "Energy, economic and environmental analysis on RET-hydrogen systems in residential buildings," Renewable Energy, vol. 33, pp. 366-382, 2008.

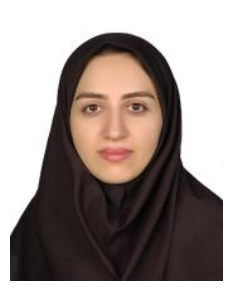

Tara Khayyamim was born in Iran in 1989. She received the MS degree from international campus of Sharif University of Technology on Kish Island, Iran in 2015. She is currently working as an research assistant at Niroo Research Institute, Tehran, Iran.

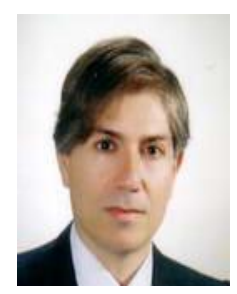

Khosrow Haj Sadeghi received his $\mathrm{PhD}$ and master degrees in electrical engineering from University of California, Irvine, California, USA. Dr. Sadeghi currently is an assistant professor in Sharif University of Technology, Tehran, Iran. His research interests include digital system design, signal processing, high speed and low power microelectronic circuits, and mixed signal system on chip design.

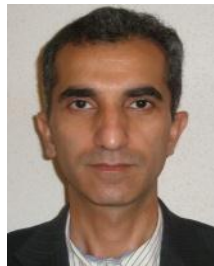

A. Zabihollah received his $\mathrm{PhD}$ degree in mechanical engineering from Concordia University, Montreal, Canada in 2007. He is the author of over 35 publications on smart structures, vibration suppression and design optimization. Dr. Zabihollah currently is with the international campus of Sharif University of Technology on Kish Island. 